06.1

\title{
Влияние межмолекулярного взаимодействия на нелинейно-оптические свойства в системах COANP-углеродные наночастицы
}

\author{
(C) C.В. Лихоманова ${ }^{1,2}$, Н.В. Каманина ${ }^{1-3}$ \\ ${ }^{1}$ АО „НПО Государственный оптический институт им. С.И. Вавилова“, Санкт-Петербург, Россия \\ 2 Петербургский институт ядерной фризики им. Б.П. Константинова НИЦ „Курчатовский институт“, \\ Гатчина, Ленинградская обл., Россия \\ ${ }^{3}$ Санкт-Петербургский государственный электротехнический университет „ЛЭТИ“, Санкт-Петербург, Россия \\ E-mail: Isv-87@bk.ru
}

Поступило в Редакцию 11 августа 2021 г.

В окончательной редакции 16 ноября 2021 г.

Принято к публикации 16 ноября 2021 г.

\begin{abstract}
Продемонстрированы основные результаты исследования нелинейно-оптических, спектральных и вольтамперных характеристик комбинированной системы, состоящей из органических молекул с сопряженными связями, относящихся к производным пиридина, и углеродных наночастиц. Показана перспективность дальнейшего изучения указанных систем в рамках мировых тенденций поиска материалов для ограничения оптического излучения.
\end{abstract}

Ключевые слова: фуллерены, комплекс с переносом заряда, оптическое ограничение излучения, органические сопряженные молекулы.

DOI: 10.21883/PJTF.2022.04.52081.18990

В связи с постоянной востребованностью защиты глаз человека (например, пилотов самолетов и др.) и технических приборов от интенсивной засветки лазерным излучением активный поиск материалов для оптического ограничения $(\mathrm{OO})$ лазерного излучения продолжает быть актуальной задачей современной науки. Актуальность темы поддерживается постоянным расширением областей применения лазерных технологий (медицина, образование, наука, бытовое использование, городская среда). Также поиску новых решений для защиты от лазерного излучения способствует развитие материаловедческих технологий, позволяющих получать новые наноструктуры и модифицировать уже известные матрицы нелинейной оптики и органической электроники.

В качестве сред для ОО излучения в настоящее время рассматриваются органические и неорганические структуры и их комбинации [1-5]: фталоцианины, полиметилметакрилат, полиимид, красители, хромофоры, биомолекулы (на примере молекул ДНК), различные наночастицы, в частности графен (оксид графена и восстановленный оксид графена), фуллерены $\left(\mathrm{C}_{60}, \mathrm{C}_{70}\right.$ и высшие), углеродные нанотрубки (одностенные и многостенные), квантовые точки, наночастицы металлов, оксидов металлов и наночастицы полупроводников.

К механизмам, приводящим к эффекту ОО, относятся двухфотонное поглощение, рассеяние, возникающее при термической реакции среды на лазерное излучение, поглощение на свободных носителях заряда, обратное насыщенное поглощение, рассеяние на дифракционной решетке за счет фоторефрактивного эффекта и др. Проявление того или иного механизма в среде зависит от характеристик падающего лазерного излучения: его длительности, мощности, режима работы (импульсный или непрерывный), длины волны, а также от самой среды (углеродные наночастицы, металлические наноструктуры, органические материалы). Например, для коротких лазерных импульсов (длительностью порядка $100 \mathrm{fs}$ ) в средах характерно проявление двухфотонного поглощения [6], индуцированного фоторефрактивного эффекта и механизма Ферстера [7]; в жидких средах при взаимодействии с длительным и мощным лазерным импульсом будет происходить образование термических центров рассеяния; при облучении углеродсодержащих матриц наносекундными лазерными импульсами с низкой энергией проявляется обратное насыщенное поглощение, а при облучении их лазерными импульсами более высокой интенсивности - двухфотонное поглощение [8]. Для сред с металлическими наночастицами характерным является поглощение свободными носителями заряда [9]. Отметим, что в реальных средах происходит конкурирование нескольких механизмов, совокупное действие которых приводит к нелинейному оптическому ограничению. В этом ключе интерес представляют именно органические сенсибилизированные материалы с внутримолекулярным комплексообразованием.

В ряде работ были рассмотрены пиридиновые органические среды (2-циклооктиламин-5-нитропиридин, COANP), сенсибилизированные углеродными наночастицами - фуллеренами $\mathrm{C}_{60}$ и $\mathrm{C}_{70}$ и восстановленным оксидом графена, а также полиимидные материалы с добавлением $\mathrm{C}_{60}$ и $\mathrm{C}_{70}[10]$. Продолжая исследование системы COANP-фуллерен, в настоящей работе мы 


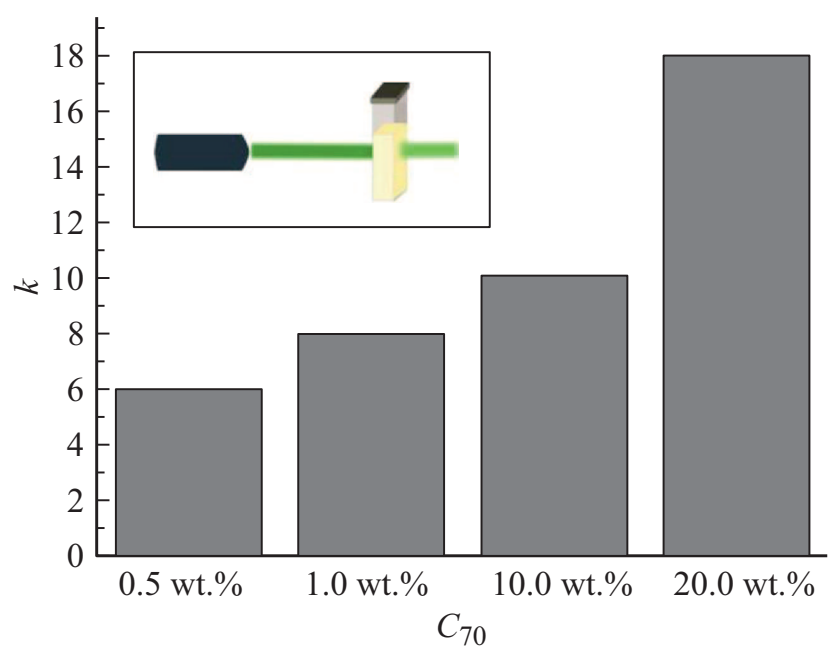

Pис. 1. Коэффициент ограничения $k$ в $1 \%$ растворе COANP в тетрахлорэтане с добавлением фуллерена $\mathrm{C}_{70}$ с концентрацией 0.5, 1.0, 10.0 и 20.0 wt.\%. На вставке - модельная схема, иллюстрирующая уменьшение интенсивности лазерного излучения видимого диапазона, прошедшего через исследуемый раствор.

взяли растворы в тетрахлорэтане с концентрацией сенсибилизатора $\mathrm{C}_{70}$ (42601, Fullerene powder 98\% $\mathrm{C}_{70}$, Alfa Aesar Company) от 0.5 до 20 wt.\% по отношению к сухой матрице COANP. На рис. 1 представлены значения коэффициента ограничения лазерного излучения $k=W_{\text {in }} / W_{\text {out }}$ для различных концентраций COANP при плотности падающей энергии $\sim 0.35 \mathrm{~J} / \mathrm{cm}^{2}$. На вставке к этому рисунку показана модельная картина, иллюстрирующая принцип оптического ограничения.

С целью расширения базы углеродных наноматериалов как эффективных сенсибилизаторов для органических молекул был рассмотрен оксид графена (Graphene oxides Ref.GO.Z.10-1.23, Nanoinnova Technologies). Графен обладает уникальными физическими характеристиками (высокая подвижность носителей заряда, прочность, теплопроводность), а также линейными и нелинейными оптическими свойствами, что позволяет рассматривать его в качестве материала для нелинейной оптики. Нами была исследована система COANP-графен, которая представлена в виде тонких пленок $(3-4 \mu \mathrm{m})$. Были вычислены фоторефрактивные параметры среды: светоиндуцированный показатель преломления $(\Delta n)$, нелинейная рефракция $\left(n_{2}\right)$ и нелинейная восприимчивость третьего порядка $\left(\chi^{(3)}\right)$ - на основе измерения дифракционной эффективности в первом порядке дифракции. Запись была произведена на пространственной частоте $90-100 \mathrm{~mm}^{-1}$. В результате были получены следующие значения: $\Delta n=0.95 \cdot 10^{-2}$, $n_{2}=4.84 \cdot 10^{-10} \mathrm{~cm}^{2} / \mathrm{W}, \chi^{(3)}=1.6 \cdot 10^{-8} \mathrm{~cm}^{3} / \mathrm{erg}$.

Наличие в средах нелинейных параметров третьего порядка влияет на процессы самовоздействия (самофокусировка, дефокусировка и др.) и фоторефракцию, под которой подразумевается формирование амплитуднофазовой дифракционной решетки, смещенной в про- странстве относительно интерференционных полос падающего лазерного излучения. Последний эффект может применяться для записи дифракционных решеток, создания элементов памяти, а также использоваться для оптического ограничения, так как на порядках дифракции будет происходить дополнительное рассеяние падающего излучения.

При обсуждении механизмов оптического ограничения для систем на основе органических молекул, сенсибилизированных углеродными наночастицами, необходимо уделить внимание образованию межмолекулярного комплекса с переносом заряда (КПЗ). Молекула COANP состоит из донорной $(\mathrm{NH})$ и акцепторной $\left(\mathrm{NO}_{2}\right)$ групп и является внутримолекулярным комплексом с переносом заряда. Энергия сродства к электрону для $\mathrm{NO}_{2}$ составляет $0.45 \mathrm{eV}$. Фуллерен имеет энергию сродства к электрону $2.67-2.68 \mathrm{eV}$, что позволяет ему при взаимодействии с донорно-акцепторной молекулой COANP аккумулировать на себе заряд с донорной части органической молекулы и образовать межмолекулярный КПЗ. Теоретическая возможность образования КПЗ в системе COANP-фуллерен была рассмотрена в работе [11]. С помощью метода Хартри-Фока было показано образование КПЗ в системах и с $\mathrm{C}_{60}$, и с $\mathrm{C}_{70}$. В работах $[12,13]$ было экспериментально подтверждено образование КПЗ с помощью спектрометрических исследований и ДСК-анализа. В полученных спектрах наблюдались сдвиг в длинноволновую область и углубление окраски исследуемых сред, что объясняется смещением электронной плотности при образовании КПЗ. Результаты ДСК-анализа демонстрируют сдвиги фазовых переходов в область более высоких температурных значений в зависимости от роста концентраций молекул $\mathrm{C}_{70}$. Также косвенным подтверждением КПЗ являются полученные вольт-амперные характеристики для COANP и $\mathrm{COANP}-\mathrm{C}_{70}$. Сенсибилизация фуллереном приводит к нелинейным вольт-амперным характеристикам (кривые 1,2 на рис. 2), на основании полученных результатов можно сделать вывод об увеличении подвижности носителей заряда и электропроводности, что сопровождается эффективным переходом электронов из зоны генерации в неосвещенную область с последующим захватом носителей в темновой области.

Образование межмолекулярного КПЗ реализуется не только в системах COANP-фуллерен, но и в других органических сопряженных матрицах, сенсибилизированных наноструктурами с более высокими значениями энергии сродства к электрону, чем в случае внутримолекулярного КПЗ [14].

Проанализировав результаты исследований по поиску материалов для ограничения оптического излучения, проводимых в последние годы мировыми научнотехническими группами, можно сделать вывод об актуальности и перспективности использования изучаемых систем. В качестве материалов для нелинейной оптики могут быть рассмотрены $\pi$-сопряженные органические 


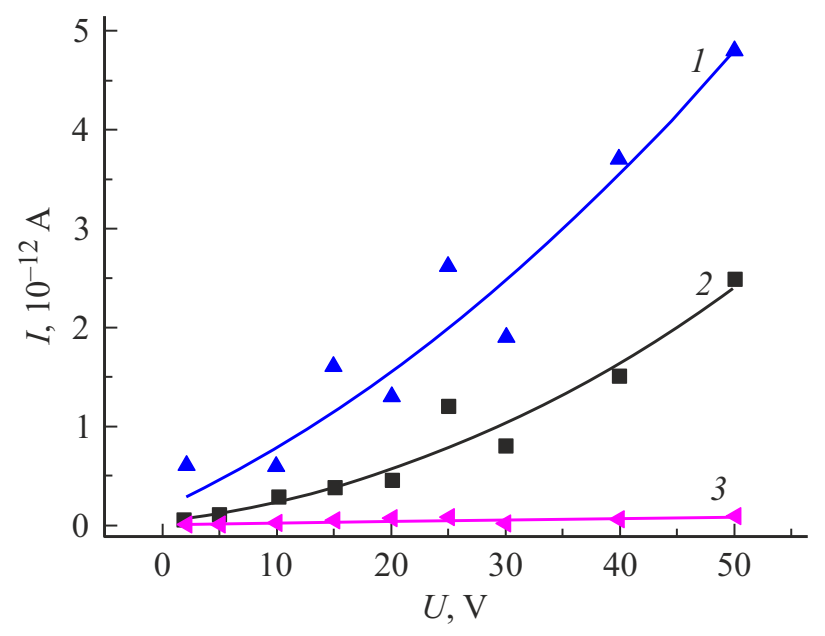

Рис. 2. Вольт-амперные характеристики: 1 COANP + 5 wt.\% $\mathrm{C}_{70}$ при засветке; $2-\mathrm{COANP}+5$ wt.\% $\mathrm{C}_{70}$, темновой режим; 3 - чистая матрица COANP.

молекулы (COANP), сенсибилизированные углеродными наночастицами (фуллерены, углеродные нанотрубки, восстановленный оксид графена).

\section{Конфликт интересов}

Авторы заявляют, что у них нет конфликта интересов.

\section{Список литературы}

[1] A. Kumar Singh, T.-Ch. Jen, Micro and Nanosystems, 13 (1), 74 (2021). DOI: 10.2174/1876402912999200805164359

[2] B.S. Ragunath, K. Sangeetha, R.R. Babu, Cryst. Res. Technol., 55 (4), 1900190 (2020). DOI: 10.1002/crat.201900190

[3] Y.-J. Liu, Q.-H. Li, D.-J. Li, X.-Zh. Zhang, W.-H. Fang, J. Zhang, Angew Chem Int. Ed., 60 (9), 4849 (2021). DOI: 10.1002/anie.202012919

[4] S.J. Varma, J. Kumar, Y. Liu, K. Layne, J. Wu, C. Liang, Y. Nakanishi, A. Aliyan, W. Yang, P.M. Ajayan, J. Thomas, Adv. Opt. Mater., 5 (24), 1700713 (2017). DOI: 10.1002 /adom.201700713

[5] C.S. Hege, O. Muller, L. Merlat, J. Appl. Polymer Sci., 136 (10), 47150 (2019). DOI: 10.1002/app.47150

[6] S. Perumbilavil, A. López-Ortega, G. Kumar Tiwari, J. Nogues, T. Endo, R. Philip, Small, 14 (6), 1701001 (2018). DOI: $10.1002 / \mathrm{smll} .201701001$

[7] N.V. Kamanina, S. Putilin, D. Stasel'ko, Synth. Met., 127 (1-3), 129 (2002). DOI: 10.1016/S0379-6779(01)00602-6

[8] R. Kumar, A. Kumar, N. Verma, V. Khopkar, R. Philip, B. Sahoo, Appl. Nano Mater., 3 (9), 8618 (2020). DOI: $10.1021 /$ acsanm.0c01284

[9] P. Nancy, J. Jose, N. Joy, S. Valluvadasan, R. Philip, R. Antoine, S. Thomas, N. Kalarikkal, Nanomaterials, 11 (4), 880 (2021). DOI: 10.3390/nano1 1040880

[10] N.V. Kamanina, S.V. Serov, N.A. Shurpo, S.V. Likhomanova, J. Mater. Sci.: Mater. Electron., 23 (8), 1538 (2012).

DOI: $10.1007 / \mathrm{s} 10854-012-0625-9$
[11] Н.В. Каманина, Е.Ф. Шека, Оптика и спектроскопия, 96 (4), 659 (2004). [N.V. Kamanina, E.F. Sheka, Opt. Spectrosc., 96 (4), 599 (2004). DOI: 10.1134/1.1719152].

[12] С.В. Лихоманова, Н.В. Каманина, Опт. журн., 83 (6), 55 (2016). [S.V. Likhomanova, N.V. Kamanina, J. Opt. Technol., 83 (6), 369 (2016). DOI: 10.1364/JOT.83.000369].

[13] S.V. Likhomanova, N.V. Kamanina, J. Phys.: Conf. Ser., 741 (1), 012146 (2016). DOI: $10.1088 / 1742-6596 / 741 / 1 / 0121462016$

[14] G. Zhao, G. Wei, W. Zhu, F. Ke, S. Guang, F. Zhang, H. Xu, J. Appl. Polymer Sci., 135 (18), 46100 (2018). DOI: $10.1002 /$ app.46100 